\title{
Armazenamento de água e densidade do solo sob três condições de superfície, em um Cambissol gleico de Lugo, Espanha
}

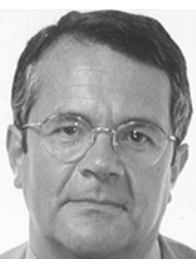

Antonio P. González \& Marlene C. Alves²

\author{
1 Depto. Ciencias de la Navegación y de la Tierra, Facultad de Ciencias. Universidad de A Coruña, A Coruña, España \\ Fone: (34) 981-167000 - R: 2110/2102,E-mail: tucho@udc.es \\ ${ }^{2}$ Depto. de Fitossanidade Engenharia Rural e Solos, UNESP, Ilha Solteira, SP. Fone(18) 3743-1143, E-mail: \\ mcalves@agr.feis.unesp.br
}

Protocolo 178 - 14/11/2003 - Aprovado em 14/5/2004

\begin{abstract}
Resumo: Objetivou-se, com o presente trabalho, investigar as variações de armazenamento de água e da densidade do solo de um Cambissol gleico, em Lugo, Espanha, sob três condições de superfície. A avaliação do teor de água e da densidade do solo no campo foi acompanhada com leituras durante 16 meses, usando-se uma sonda de nêutrons gama. Três condições de superfícies foram estudadas: pastagem (Lolium perenne) com 4 anos; pastagem com 2 anos e solo descoberto. As avaliações foram realizadas nas profundidades de 0,20, 0,30, 0,60 e 1,20 m. Com base nos resultados, concluiu-se que: as condições de superfície proporcionaram diferenças no armazenamento de água, até a profundidade de 0,60 m; as variações de armazenamento de água influenciaram a avaliação da densidade do solo; a superfície com o solo descoberto apresentou menor variação no conteúdo de água armazenada enquanto a superfície com a pastagem de 4 anos mostrou maior variação.
\end{abstract}

Palavras-chave: propriedades físicas do solo, sonda de nêutrons gama, retenção de água

\section{Soil water storage and bulk density under three conditions of soil surface in a Cambisol of Lugo, Spain}

\begin{abstract}
The present work aimed to investigate the soil water storage and bulk density of a Cambisol gleico in Lugo, Spain, with three conditions of soil surface. Thus, the main objective was to study the conservation of the water in the soil. In order to evaluate the soil water content and bulk density, readings were accomplished during 16 months, using a neutron gamma probe under the field conditions. Three plots were used: plot 1 - pasture (Lolium perenne) with 4 years; plot 2 - pasture (Lolium perenne) with 2 years and plot 3 - bare soil. The obtained data at depths of $0.20,0.30,0.60$ and $1.20 \mathrm{~m}$ were discussed. Results show that soil surface conditions were different in the soil water storage until the depth of $0.60 \mathrm{~m}$; the variations of soil water storage influenced the bulk density. Soil water storage variations were lower for the bare soil and higher for the soil surface under 4 year pasture.
\end{abstract}

Key words: physical properties of soil, neutron gamma probe, soil water retention

\section{INTRODUÇÃO}

Em função do manejo a que está submetido, o solo tanto é passível de degradação quanto de melhoramento, em seu potencial produtivo. Quando ocorre a degradação da estrutura do solo, tem-se como efeito imediato o aumento da sua densidade, diminuição da macroporosidade e armazenamento de água ao longo do perfil, caracterizando a compactação desse solo (Stone \& Moreira, 2000; Alves, 2001).
A relação entre a massa e o volume do solo também pode ser alta devido a uma condição genética do solo, isto é, pela presença de horizontes ou níveis subjacentes endurecidos por processos geológicos e edafogenéticos naturais (Paz González et al., 1997).

Nessas condições de modificação da relação massa/volume do solo, quer seja natural ou antropogênica, ocorre diminuição da entrada de água no perfil do solo e no comportamento da sua redistribuição e retenção, em virtude das alterações da 
porosidade do solo, principalmente na sua distribuição de tamanho de poros (Alves, 2001).

No solo, a água ocupa os espaços porosos formados do arranjo físico das partículas da fase sólida competindo e, freqüentemente, concorrendo com a fase gasosa do solo. Da água que chega ao solo, uma parte é armazenada; a água do solo é altamente dinâmica, exibindo variação no tempo e no espaço, sobretudo perto da superfície do solo, devido à evaporação e atividade das raízes das plantas. Mudanças no conteúdo de água do solo e no seu estado de energia, afetam muito as suas propriedades mecânicas, incluindo resistência, compactabilidade e penetrabilidade, podendo causar mudanças na densidade de solos expansivos (Or \& Wraith, 2000).

A retenção de água é primariamente dependente da distribuição de tamanho de partículas do solo, estrutura, mineralogia e matéria orgânica; numa segunda consideração, o uso e o manejo do solo estarão afetando a retenção e o seu conteúdo de água no solo. O melhor aproveitamento da água capilar pode tornar-se fundamental para a melhoria das produções e das condições do solo pois, a medida em que é submetido a muitos ciclos de umedecimento e secagem, o solo pode ter suas propriedades físicas prejudicadas como, por exemplo, um aumento na densidade do solo (Fassbender, 1982).

Muitas técnicas têm sido usadas na agricultura com o objetivo de reduzir as perdas de água do solo, porém há ainda que se investigar quais são as melhores, visto que os comportamentos dos diferentes solos e climas não traduzem resultados semelhantes. Giraldes \& González (1994) encontraram que as técnicas sem preparo do solo foram muito eficientes, pois com a superfície do solo coberta todo o ano, evitaram-se grandes perdas de água por evaporação.

Os perfis de solo em parcelas de pousio contêm ao redor de $10 \%$ mais água que perfis de parcelas com cultivos, devido às menores perdas de água que sofrem as parcelas diante da ausência de consumidores potenciais (Tenorio et al., 1997; Tenorio et al., 2001; ).

Em um experimento conduzido por Foley et al. (1991) sobre um Alfisol e um Oxisol da Austrália, constatou-se que o cultivo com aração e posterior período de pousio melhorou a infiltração da água em razão do rompimento de selamentos superficiais de ambos os solos.

$\mathrm{O}$ armazenamento de água no solo varia em função da quantidade de água que entra no perfil e dos fatores que contribuem para que esta permaneça armazenada. Um deles é a condição da superfície que, inclusive irá regular a sua variação no solo. A evolução da superfície do solo é extremamente complexa e nela intervêm numerosos processos determinados pelas características da água da chuva, as propriedades físicas, mecânicas e hídricas do solo e fatores do local, como a percentagem de cobertura pela vegetação e a história prévia da evolução da superfície (Taboada Castro, 2001).

Uma crosta superficial pode apresentar-se tipicamente em solo com argilas pouco expansivas e estas podem dispersar-se quando o solo se encontrar úmido. Segundo Taboada Castro (2001) um solo com selamento superficial indica falta de conexão entre os poros da superfície e o interior do perfil, de modo que o transporte de água e ar se encontra muito limitado. Os macroporos e os poros de transmissão são obstruídos (Fiès \&
Panini, 1995) pela reorganização das partículas superficiais devido, por sua vez, ao colapso da estrutura pelos diversos mecanismos de desagregação. Com esta condição na superfície, o solo pode dar lugar à formação de uma crosta superficial.

De acordo com suas variações pedogenéticas, os solos apresentaram comportamento diferenciado quanto à dinâmica e ao armazenamento da água. Solos que apresentam mudança textural abrupta, apresentam compacidade natural em alguns níveis do subsolo contrastando, em alguns casos, com um horizonte Ap arenoso; neste sentido, desenvolveu-se este trabalho com o objetivo de investigar as variações de armazenamento de água e a influência na densidade de um Cambisol gleico, representativo da microbacia de Terra Cha, em Lugo, região da Galicia, Espanha, em três condições de superfície.

\section{MATERIAL E MÉTODOS}

Este trabalho foi desenvolvido na Granja Gaioso-Castro, em Castro de Ribeiras do Lea, em Lugo, Galicia, Espanha. A área está situada a $444 \mathrm{~m}$ de altitude com coordenadas de latitude $43^{\circ} 06^{\prime} \mathrm{N}$ e longitude $7^{\circ} 26^{\prime} \mathrm{L}$. Temperatura média anual de $11,2^{\circ} \mathrm{C}$ e precipitação total média anual de $930 \mathrm{~mm}$ (dados 1961-1990) (Paz González et al., 1996).

O solo da área experimental apresenta perfil com horizontes $\mathrm{A}_{\mathrm{p}}-\mathrm{B}_{\mathrm{w}}-\mathrm{B}_{\mathrm{tg}}$, e foi classificado, segundo os critérios da FAO (1990) e FAÖ-ISRIC (1994) como Cambisol gleico e tem como material de origem, sedimentos do Terciário/Quaternário. Na Tabela 1 apresentam-se a altitude e os dados analíticos do perfil de cada parcela (Paz González et al., 1997).

O experimento foi conduzido ao longo de 16 meses, desde o final de 1989 até março de 1991, em 3 condições de superfície: parcela 1: pastagem (azevém), semeada no ano de 1987; portanto, em 1990 encontrava-se no terceiro ano, dedicandose ao pasto para ovelhas no período das amostragens; parcela 2: pastagem (azevém), semeada no outono de 1989, depois de um cultivo de milho; no ano de 1990 foram realizados dois cortes; parcela 3: manteve-se sem vegetação ao longo do período do experimento. No dia 8 de maio de 1990, depois do primeiro corte da pastagem, aplicou-se um herbicida que eliminou totalmente as espécies distintas; a superfície do solo manteve-se limpa até março de 1991, quando começou a se observar o surgimento de vegetação espontânea.

Realizou-se o monitoramento do conteúdo de água no solo, nas seguintes profundidades: 0,$20 ; 0,30 ; 0,60$ e $1,20 \mathrm{~m}$. Nas profundidades de 0,20 e $0,30 \mathrm{~m}$, foi efetuado o monitoramento com a finalidade de caracterizar os conteúdos de água nas zonas representativas do horizonte A do solo $(0,20 \mathrm{~m})$ e da faixa de transição entre $\mathrm{A} / \mathrm{B}(0,30 \mathrm{~m})$. O conteúdo de água e a densidade do solo úmido foram avaliados com uma sonda de nêutrons gama - Campbell Pacific Nuclear, modelo 501 B, que tem densímetro gama e umidímetro de nêutrons. A fonte de raios gama consiste em $10 \mathrm{mCi} \mathrm{de}{ }^{137} \mathrm{Cs}$ e a fonte de nêutrons está constituída por $50 \mathrm{mCi} \mathrm{de}{ }^{242} \mathrm{Am}-\mathrm{Be}$, sendo o detetor $\mathrm{BF}_{3}$. $\mathrm{O}$ diâmetro da sonda é de $0,0381 \mathrm{~m}$. Uma particularidade do modelo usado está em que o centro da esfera de influência para a medida da umidade, está situado $0,22 \mathrm{~m}$ por cima do da densidade. 
Tabela 1. Altitude e dados analíticos do perfil nas parcelas com as condições de superfície estudada.

\begin{tabular}{|c|c|c|c|c|c|c|c|c|}
\hline Parcela & $\begin{array}{l}\text { Altitude } \\
\mathrm{m}\end{array}$ & Horizonte & $\begin{array}{l}\text { Profundidade } \\
\text { m }\end{array}$ & $\begin{array}{l}\text { Carbono } \\
\mathrm{g} \mathrm{dm}^{-3}\end{array}$ & Areia & Silte & $\begin{array}{l}\text { Argila } \\
\mathrm{g} \mathrm{kg}^{-1}\end{array}$ & Cascalhos \\
\hline \multirow[t]{3}{*}{1} & 414,5 & Ap & $0-0,35$ & 54,7 & 585 & 217 & 198 & 310 \\
\hline & & $\mathrm{Bw}$ & $0,35-0,70$ & 4,9 & 488 & 151 & 361 & 423 \\
\hline & & $2 \mathrm{Btg}$ & $>0,70$ & 4,2 & 268 & 324 & 408 & - \\
\hline \multirow[t]{3}{*}{2} & 415,5 & Ap & $0-0,35$ & 50,5 & 634 & 191 & 175 & 370 \\
\hline & & $\mathrm{Bw}$ & $0,35-0,70$ & 7,2 & 591 & 207 & 192 & 448 \\
\hline & & $2 \mathrm{Btg}$ & $>0,70$ & 2,6 & 241 & 280 & 479 & - \\
\hline \multirow[t]{4}{*}{3} & 424,5 & Ap & $0-0,35$ & 57,8 & 554 & 261 & 185 & 213 \\
\hline & & $\mathrm{Bw}$ & $0,35-0,80$ & 3,5 & 497 & 196 & 307 & 479 \\
\hline & & $\mathrm{BC}$ & $0,80-1,50$ & 1,6 & 461 & 214 & 325 & 410 \\
\hline & & $2 \mathrm{Btg}$ & $>1,50$ & 5,8 & 230 & 302 & 468 & - \\
\hline
\end{tabular}

Foram utilizados tubos de alumínio comercial para acesso da sonda, com diâmetro interno de $0,040 \mathrm{~m}$ e externo de $0,045 \mathrm{~m}$.

O umidímetro foi calibrado com o conteúdo hídrico determinado por gravimetria no solo estudado, enquanto o densímetro o foi a partir de materiais com padrão de densidade conhecido (Paz González et al., 1994).

A densidade do solo seco, foi obtida a partir da densidade do solo úmido $\left(\mathrm{ds}_{\mathrm{w}}\right)$ e do conteúdo de água volumétrica $(\theta)$, segundo a equação:

$$
\mathrm{ds}=\mathrm{ds}_{\mathrm{w}}-\mu \theta
$$

A constante de correção $(\mu)$ da densidade do solo úmido é medida por retroespalhamento de raios gama. Esta constante expressa a diferença entre o coeficiente de atenuação da radiação gama entre a água $\left(0,0776 \mathrm{~cm}^{2} \mathrm{~g}^{-1}\right)$ e do solo $(0,0856$ $\mathrm{cm}^{2} \mathrm{~g}^{-1}$ ) sendo $\mu=1,113$ (Paz González et al., 1997).

\section{RESULTADOS E DISCUSSÃO}

Na Figura 1 (A, B e C) apresentam-se os resultados encontrados para as relações entre o teor de água e a densidade do solo, nas três condições de superfície estudadas, para a profundidade de $0,20 \mathrm{~m}$. Comparando as três condições de superfície, observa-se que no período estudado, as parcelas 1 (pastagem com 4 anos) e 2 (pastagem com 2 anos), apresentaram variação do teor de água entre 0,08 a $0,39 \mathrm{~m}^{3} \mathrm{~m}^{-3}$, enquanto a parcela 3 (solo descoberto) variou entre 0,17 a 0,32 $\mathrm{m}^{3} \mathrm{~m}^{-3}$, aproximadamente. A densidade do solo para as parcelas 1 e 2 ficou entre 0,70 e $1,20 \mathrm{~kg} \mathrm{dm}^{-3}$ e na parcela 3 entre $0,92 \mathrm{e}$ $1,25 \mathrm{~kg} \mathrm{dm}^{-3}$.

Nas parcelas com vegetação (pastagem) a variação da umidade, no período estudado, foi de $0,31 \mathrm{~m}^{3} \mathrm{~m}^{-3} \mathrm{e}$, na parcela com o solo descoberto, foi de $0,15 \mathrm{~m}^{3} \mathrm{~m}^{-3}$. A taxa de evaporação de uma superfície de solo úmido depende da energia disponível para o processo e de outros fatores meteorológicos, porém a evaporação pode estar limitada pelo movimento de água no solo até a superfície evaporante (Ramírez \& López, 1993). Quando as taxas de evaporação são baixas, a existência de um gradiente de potencial devido à proximidade da lâmina de água armazenada e a condutividade hidráulica do solo, são suficientes para manter a superfície úmida e a evaporação só está limitada por causas meteorológicas; ao contrário, se as taxas de evaporação são altas, a velocidade de evaporação é

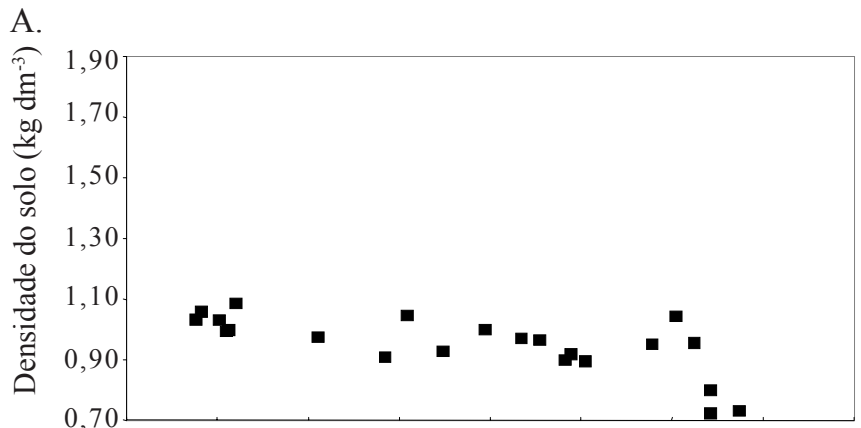

B.

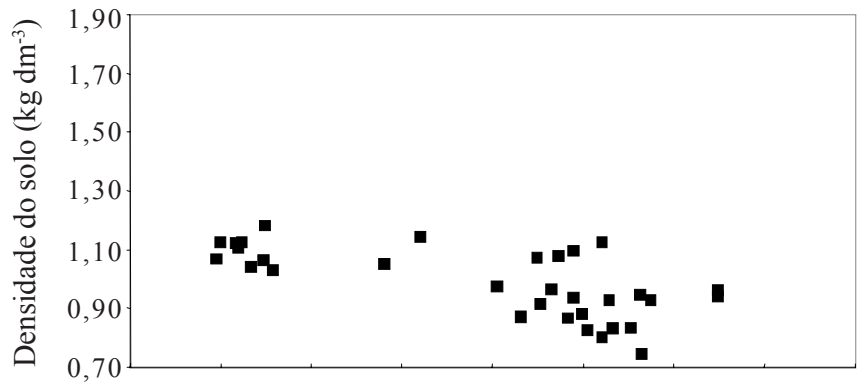

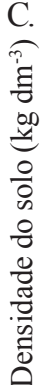

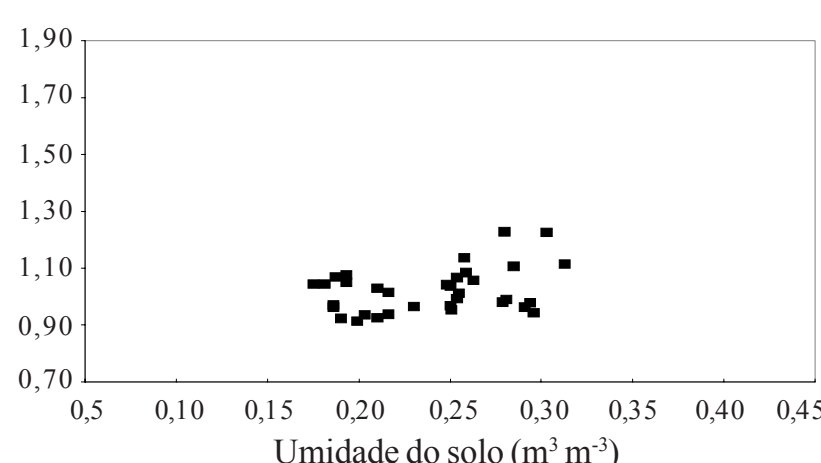

Figura 1. Relação entre o teor de água e a densidade do solo, para a profundidade de $0,20 \mathrm{~m}$, para: (A) pastagem com 4 anos, (B) pastagem com 2 anos e (C) solo descoberto

superior à velocidade de ascensão capilar da água, regulando a velocidade de evaporação e quando as plantas se instalam sobre o solo, sua ação eqüivale a prolongar o período de evaporação rápida, enquanto, na zona explorada pelas raízes, a umidade do solo desce até o ponto de murchamento; portanto, a variação no conteúdo de água $\left(0,15 \mathrm{~m}^{3} \mathrm{~m}^{-3}\right)$ foi menor na parcela 3 (solo descoberto), fato explicado pela evaporação mais lenta devido à não existência de plantas e, possivelmente, 
à formação de uma crosta superficial, contrastando com 0,31 $\mathrm{m}^{3} \mathrm{~m}^{-3}$, das áreas com pastagem.

Em geral, a crosta não apresenta conexão entre os poros da superfície do solo e o interior do perfil, de modo que o transporte de água e ar se encontra limitado, visto que poros de transmissão são obstruídos pela reorganização das partículas superficiais, pelo colapso da estrutura pelos diversos mecanismos de desagregação (Fiès \& Panini, 1995; Taboada Castro, 2001).

A variação da densidade do solo foi maior nas parcelas onde a variação do armazenamento de água também foi maior (parcelas 1 e 2). As diferenças verificadas quanto a densidade, podem estar relacionadas à quantidade de matéria orgânica; segundo Paz González et al. (1997), é necessário considerar que o preparo profundo do solo promove mescla de horizontes ricos em matéria orgânica com os horizontes minerais subjacentes; outro fator é que nem sempre os métodos radioativos que medem a densidade do solo atingem o mesmo volume de solo. A esfera de influência dos nêutrons varia com o teor de água no solo, além do fato deles amostrarem um grande volume de solo, que não é bem definido (assume-se uma esfera de 0,20 a 0,30 m de diâmetro) (Freitag, 1971; Erbach, 1987). Outro aspecto é que se a sonda explora um grande volume de solo, nunca se sabe se toda a esfera de influência foi submetida uniformemente ao secamento ou ao molhamento. Esse fato se torna mais grave em solos heterogêneos como nos perfis estratificados e pedregosos (Bacchi \& Reichardt, 1990).

$\mathrm{Na}$ área de estudo, os solos foram desenvolvidos sobre materiais sedimentares do terciário-quaternário. Trata-se de sedimentos miopliocênicos, em cuja parte superior se apreciam camadas alternantes de materiais argilosos e arenosos, freqüentemente recobertos por um manto quaternário mais ou menos espesso. Esses solos apresentam mudanças texturais abruptas (Castelao Gegunde \& Diaz-Fierras, 1992; Paz González et al., 1997); são solos, portanto, que não apresentam materiais minerais expansivos.

Na Figura 2 observa-se a variação entre o conteúdo de água e a densidade do solo para as três condições de superfície estudadas, na profundidade de $0,30 \mathrm{~m}$. Nesta profundidade também ocorreu menor variação do teor de água para o período estudado, na parcela com o solo descoberto, variando de 0,18 a $0,32 \mathrm{~m}^{3} \mathrm{~m}^{-3}$; já o solo com a parcela 1 (pastagem com 4 anos) apresentou, comparado à parcela 2 (pastagem com 2 anos), maior variação do teor de água, no período estudado, e maior teor de água armazenada $\left(0,42 \mathrm{~m}^{3} \mathrm{~m}^{-3}\right.$ contra $\left.0,33 \mathrm{~m}^{3} \mathrm{~m}^{-3}\right)$; este fato pode estar relacionado a mudanças na composição do solo e na sua relação massa e volume. Para a profundidade de $0,35 \mathrm{~m}$ o solo da parcela 2 tem mais areia e menos argila, o que explica o menor conteúdo total de água armazenada (Tabela 1). Com relação à variação da densidade do solo, pode-se constatar, na Figura 2, que a parcela 1 foi a que apresentou maior amplitude de variação para a densidade do solo e para o teor de água, cujos resultados reforçam o comportamento obtido para a profundidade de $0,30 \mathrm{~m}$.

Quanto aos valores de densidade do solo, a parcela 3 (solo descoberto) foi a que apresentou menor variação, considerando-se as profundidades de 0,20 e $0,30 \mathrm{~m}$; este fato ocorreu provavelmente porque também foi esta parcela que manteve o teor de água semelhante nas duas profundidades
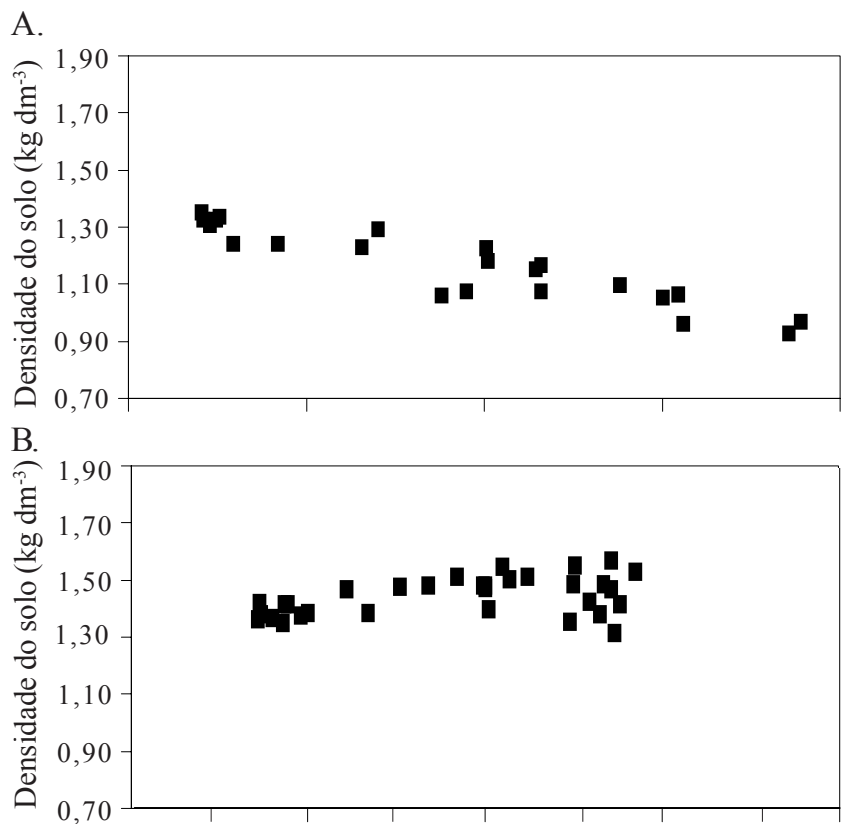

C.

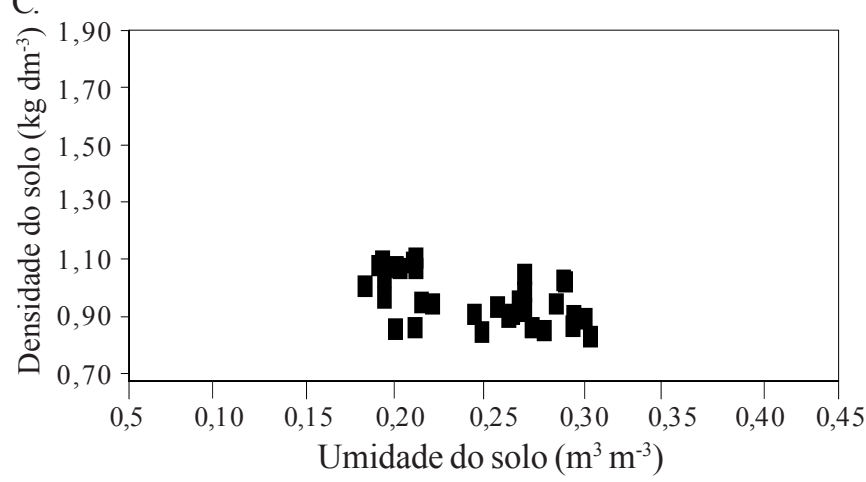

Figura 2. Relação entre o teor de água e a densidade do solo para a profundidade de $0,30 \mathrm{~m}$, para (A) pastagem com 4 anos, (B) pastagem com 2 anos e (C) solo descoberto

contribuindo, desta forma, para menor variação da metodologia adotada, visto que a mudança no teor de água afeta a esfera de alcance dos nêutrons emitidos pela sonda. Salienta-se que, nesta parcela, o solo também se apresentou mais homogêneo quanto à sua composição física (Tabela 1).

Os valores da densidade do solo para as parcelas 1 e 2 foram maiores que os verificados para a profundidade de $0,20 \mathrm{~m}$ (Figura 2); ressalta-se que no caso da parcela 2, as diferenças foram maiores (de $0,75 \mathrm{a} 1,18 \mathrm{~kg} \mathrm{dm}^{-3}$ para 1,31 a 1,56 $\mathrm{kg} \mathrm{dm}^{-3}$ ); esses resultados parecem ser independentes do tipo de material que se encontra em profundidade (Paz González et al., 1997) e podem estar relacionados com a compacidade natural do solo. Observa-se que o conteúdo de água na parcela 2 (Figuras 1B e 2B), ficou mais agrupado entre 0,25 e $0,35 \mathrm{~m}^{3} \mathrm{~m}^{-3}$ e entre $0,12 \mathrm{e} 0,33 \mathrm{~m}^{3} \mathrm{~m}^{-3}$, respectivamente, porém tendo valores dispersos entre $0,10 \mathrm{a} 0,38 \mathrm{~m}^{3} \mathrm{~m}^{-3}$. Sabe-se que à medida que $\mathrm{o}$ solo é submetido a muitos ciclos de umedecimento e secamento, este pode ter suas propriedades físicas prejudicadas como, por exemplo, aumento na densidade do solo (Fasbender, 1982).

Na Figura 3 observam-se os resultados referentes à relação entre a variação do teor de água e a variação da densidade do solo, nas parcelas estudadas, para a profundidade de $0,60 \mathrm{~m}$. 
A.

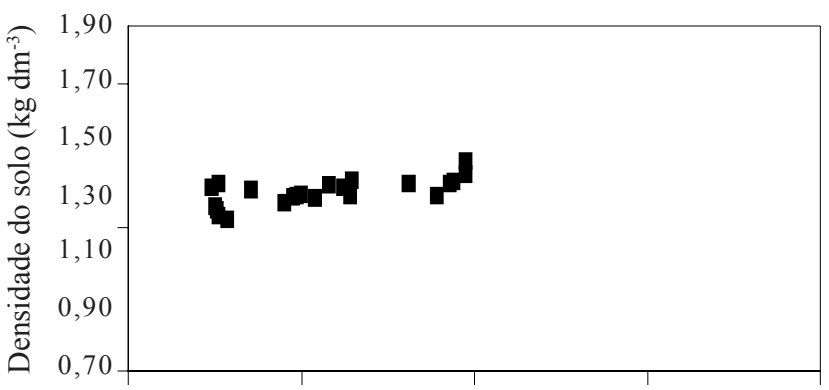

B.

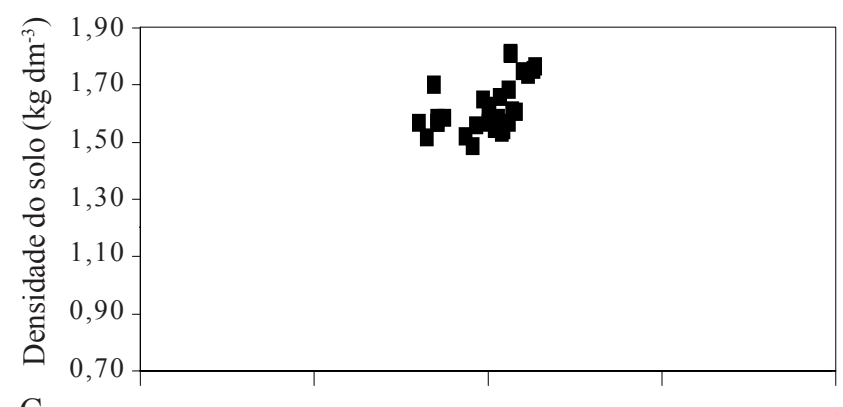

C.

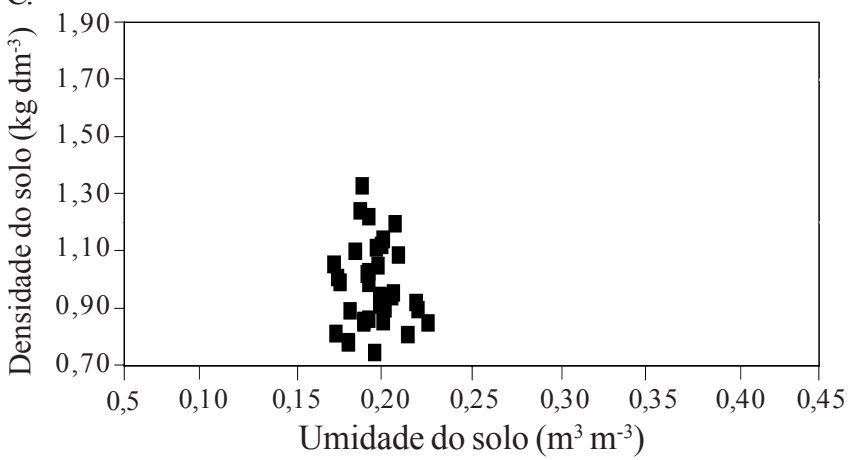

Figura 3. Relação entre o teor de água e a densidade do solo para a profundidade de $0,60 \mathrm{~m}$, para (A) pastagem com 4 anos, (B) pastagem com 2 anos e (C) solo descoberto

O comportamento da variação do teor de água no período estudado, foi semelhante ao verificado para a profundidade de $0,30 \mathrm{~m}$, isto é, na parcela com pastagem de 4 anos a variação de umidade foi maior.

Quanto à densidade do solo (Figura 3), constatou-se comportamento inverso ao da profundidade de $0,60 \mathrm{~m}$, comparando-se às profundidades de 0,20 e 0,30 m, ou seja, a parcela 3 (solo descoberto) foi a que apresentou maior amplitude de variação; para as três condições de superfície, a variação do teor de água foi menor, fato este relacionado com a profundidade de estudo do solo $(0,60 \mathrm{~m})$, visto que a esta profundidade ocorre menor influência dos fatores climáticos que, por sua vez, regulam a evaporação da água nas camadas superficiais do solo e na condição do solo estudado, por haver um gradiente de textura que se inicia, em média, a 0,70 m (Tabela 1), ocasionando descontinuidade dos microporos, devido à diferença de textura dos horizontes superficiais do solo para os subsuperficiais quebrando, assim, a capilaridade. Este fato contribuiu para o maior armazenamento de água nas camadas mais profundas e, conseqüentemente, ocorre menor perda por evaporação.
Na Figura 3 nota-se que, para as três parcelas estudadas, na profundidade de $0,60 \mathrm{~m}$ os valores de densidade do solo foram superiores aos verificados nas duas profundidades anteriores $(0,20$ e $0,30 \mathrm{~m})$. Densidades tão altas correspondem a um grau elevado de compacidade natural, que se podem apresentar em camadas ou horizontes de origem muito diversa, como são as formações de till, fragipan ou ortstein (Paz Gonzaléz, 1997). Solos que, durante a sua gênese passaram pelo fenômeno de eluviação dando origem a horizonte argílico ou textural $\left(\mathrm{B}_{\mathrm{t}}\right)$, apresentam camadas adensadas que se formam devido à translocação da argila. A argila é translocada pelos poros médios e grandes ou em fendas, a deposição ocorre quando os poros maiores não têm continuidade e a água filtra para poros menores, depositando-se as partículas nas paredes dos agregados. Forma-se, portanto, o horizonte B textural, que apresenta alta densidade e resistência mecânica (Kämpf et al., 1985).

Quando se analisa a relação entre o teor de água e a densidade do solo na profundidade de $1,20 \mathrm{~m}$, nota-se um comportamento semelhante tanto com relação à variação da umidade como com relação à variação da densidade do solo, nas três condições de superfície estudadas, ou seja, ocorre pequena variação, como pode ser observado na Figura 4. Nesta

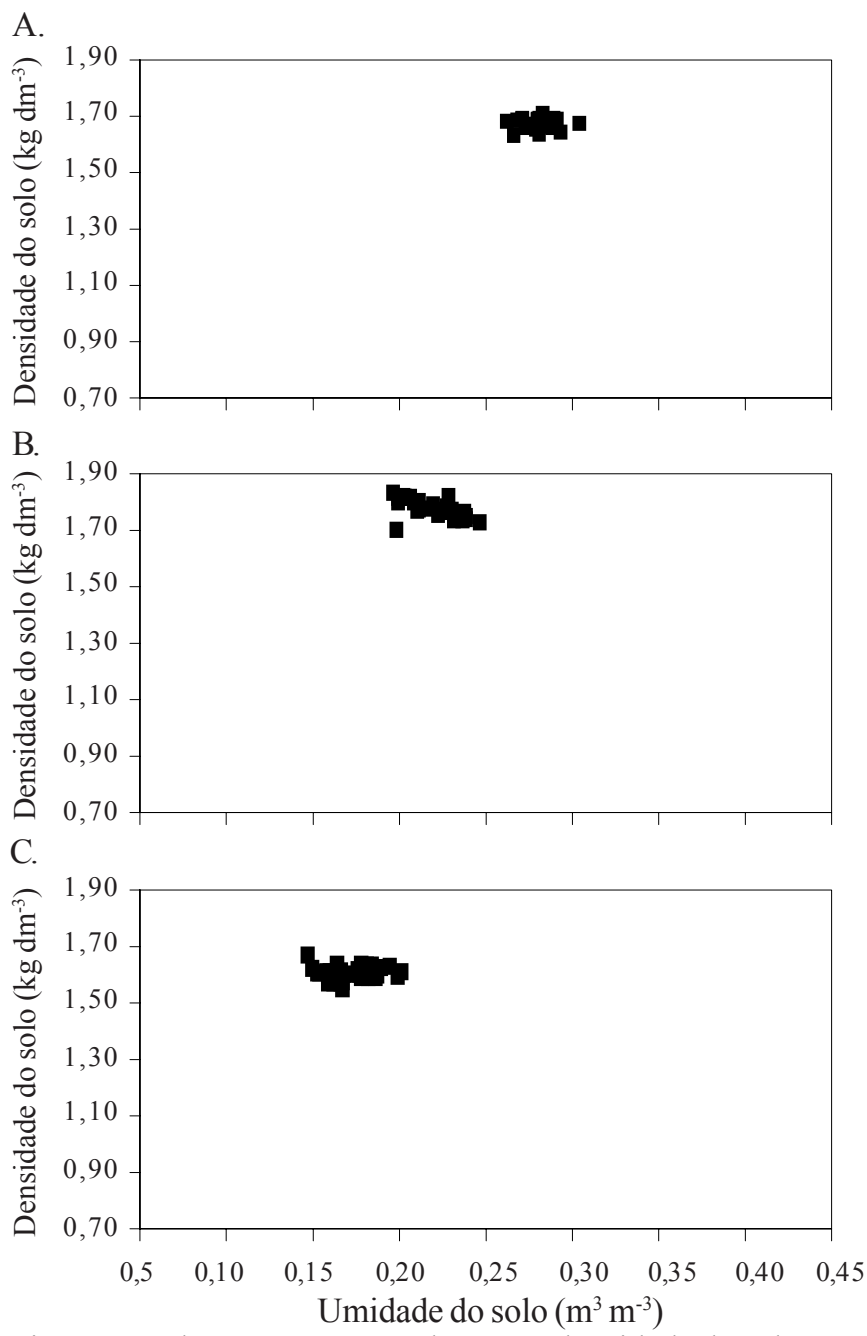

Figura 4. Relação entre o teor de água e densidade do solo para a profundidade de $1,20 \mathrm{~m}$, para (A) pastagem com 4 anos, (B) pastagem com 2 anos e (C) solo descoberto 
profundidade, os valores de densidade do solo foram mais altos que nas demais profundidades estudadas. Além dos fatores mencionados para a profundidade de $0,60 \mathrm{~m}$, acrescentase também a ação de processos de cimentação química, de acordo com Paz González et al. (1997).

Na profundidade de $1,20 \mathrm{~m}$ a variação da densidade do solo foi menor devido, provavelmente, à menor variação do teor de água, contribuindo para melhor eficiência e menor variabilidade de resultados na avaliação da densidade, pelo método da emissão de raios gama (Freitag, 1971; Erbach, 1987); à menor variação do teor de água a esta profundidade, que contribuiu para menores influências nas propriedades físicas relacionadas a ciclos de umedecimento e secamento (Fassbender, 1982; Or \& Wraith, 2000).

\section{CONCLUSÕES}

1. As condições de superfície pastagem com 4 anos, pastagem com 2 anos e solo descoberto, influenciaram a variação de armazenamento da água do solo até a profundidade de $0,60 \mathrm{~m}$.

2. A variação do armazenamento da água influenciou a densidade do solo, avaliada pelo método de emissão de raios gama.

3. A superfície com solo descoberto evidenciou menor variação no teor de água armazenada.

4. A superfície com pastagem por 4 anos mostrou maior variação no teor de água do solo.

\section{LITERATURA CITADA}

Alves, M.C. Recuperação do subsolo de um Latossolo Vermelho usado para terrapleno e fundação da usina hidrelétrica de Ilha Solteira, SP. Ilha Solteira. 2001. Ilha Solteira: UNESP, 83p. Tese Livre Docente

Bacchi, O.O.S.; Reichardt, K. A sonda de nêutrons e seu uso na pesquisa agronômica, Piracicaba: USP. Escola Superior de Agricultura "Luiz de Queiroz", 1990. 84p.

Castelao Gegunde, A. Diaz-Fierros, F. Os solos de Terra Chá. Tipos. Xénese e aproveitamento. Lugo: Publicación Diputación Provincial de Lugo. 1992. 166 p.

Erbach, D.C. Measurement of soil bulk density and moisture. Transaction of the ASAE. St. Joseph, v.30, p. 922-931, 1987.

FAO. Soil map of the world. Revised legend. Rome, 1990. 119p.

World Resources Report $\mathrm{n}^{\circ} 60$

FAO. World reference base for soil resources. Rome. 1994. 161p.

Fassbender, H.W. Química de suelos, con ênfasis en suelos de América Latina. San Jose: IICA. 1982. 422p.
Fiès, J.C; Panini, T. Infiltrabilité et charactéristiques physiques des croûtes formées sur massifs d'agrégats initialement secs ou humides soumis a dès pluies simulées. Agronomie, Paris, v.1, p.205-220, 1995.

Foley, J. L.; Loch, R. L.; Glanville, S. F.; Connolly, R. D. Effects of tillage, stubble and rainfall energy on infiltration. Soil and Tillage Research. Amsterdam. v.20, p. 45-55, 1991.

Freitag, D.R. Methods of measuring soil compaction. In: Compaction of agricultural soils. St. Joseph: ASAE. 1971. p. 47-103.

Giráldez, J.V.; González, P. No tillage in clay soil under mediterranean climate: Physical aspects. In: Experience with the applicability of no tillage crop production in the West European countries. EC-Workshop,Giessen, 1. p. 111-117, 1994.

Kämpf, N.; Schneider, P.; Klamt, E. Introdução à ciência do solo. Porto Alegre: Universidade Federal do Rio Grande do Sul/Faculdade de Agronomia. 1985.61p

Or, D.; Wraith, J.M. Soil water content and water potential relationships. In: Sumner, M. E. (ed.) Handbook of Soil Science. Boca Raton, Washington. p. A-53-A-85, 2000.

Paz González, A.; Neira Seijo, X.; Castelao Gegunde, A. Calibrado de un humidimetro de neutrons y densímetro gamma. Revista Real Academia Galega de Ciencias. Santiago de Compostela, v.13, p.125-140, 1994.

Paz González, A.; Neira, A.; Castelao, A. Soil water regime under pasture in the humid zone of Spain: validation of an empirical model and prediction of irrigation requirements. Agricultural Water Management, Amsterdam, v. 29, p.147-161, 1996.

Paz González, A.; Neira Seijo, X.; Benito Rueda, E. Compacidad de los suelos desarrollados sobre sedimentos TerciarioCuaternarios en Terra Cha (Lugo). Caderno Lababoratorio Xeolóxico de Laxe, Sada, La Coruña, v.22, p.15-28, 1997.

Ramírez, A.A.; López, R.G. El agua en el Suelo. In: Mañas, F.M.S.O.; Valero, J.A. Agronomia del riego. Mundi-Prensa: Ediciones Madrid. 1993.p.19-69.

Stone, L.F.; Moreira, J.A.A. Efeitos do sistema de preparo do solo no uso da água e na produtividade do feijoeiro. Pesquisa Agropecuária Brasileira, Brasília, v.35, n.4, p.835-841, 2000.

Taboada Castro, M. M. Morfología de superficies cultivadas. En relación con la infiltración, la formación del excedente de agua y la erosión. La Coruña: UDC, 2001. 541p. Tesis Doctoral

Tenorio, J.L.; Lucena, J.J.; Muñoz Guerra, L.M.; Ayerbe, L. Effects of crop rotation and different tilling system on barley culture in Spanish central plains. In: Congress European Society for Agronomy, 5. Actas, Madri, 1997.

Tenorio, J.L.; Catalám, G.; De Andrés, E.F.; Sánchez, J.; Ayerbe, L. Eficiencia en el uso del agua de diferentes cultivos bajo la aplicación de diferentes tratamientos de laboreo. In: World Congress on Conservation Agriculture, 1, Madri, 2001. p. 609-613. 